\title{
Evaluation of a challenge testing protocol to assess the stability of ready-to-eat cooked meat products against growth of Listeria monocytogenes
}

\author{
M. Uyttendaele*, A. Rajkovic, G. Benos, K. François, F. Devlieghere, J. Debevere \\ Laboratory of Food Microbiology and Food Preservation, Faculty of Agricultural and Applied Biological Sciences, Gent University, \\ Coupure Links 653, B-9000 Ghent, Belgium
}

Received 2 January 2003; received in revised form 22 April 2003; accepted 30 May 2003

\begin{abstract}
Challenge testing of ready-to-eat (RTE) foods with Listeria monocytogenes is recommended to assess the potential for growth. The present study was undertaken to evaluate a protocol for challenge testing applied to RTE cooked meat products. In order to choose L. monocytogenes strains with a representative behaviour, initially, the variability of the response of multiple $L$. monocytogenes strains of human and food origin to different stress and growth conditions was established. The strains were not inhibited in their growth at moderate acid $\mathrm{pH}$ (5.25) and the four strains tested in particular showed a similar acid-adaptive response. Growth of the various strains under four different combined stress conditions indicated that no L. monocytogenes strain had consistently significant longer or shorter lag phase or higher or lower maximum specific growth rates. The effect of choice of strain and history (pre-incubation temperature 7 or $30^{\circ} \mathrm{C}$ ) on growth of L. monocytogenes under optimum conditions (Brain Heart Infusion, BHI) and modified BHI simulating conditions of cooked ham and paté was studied. In general, all four $L$. monocytogenes strains behaved similarly. In BHI, no difference in lag phase was observed for the cold-adapted and standard inoculum, whereas in BHI adjusted to ham and pâté conditions, a ca. 40-h reduction of the lag phase was noted for the coldadapted inoculum. Subsequently, microbial challenge testing of L. monocytogenes in modified atmosphere packaged sliced cooked ham and paté was performed. A mixed inoculum of four L. monocytogenes strains and an inoculum level of ca. 1-10 $\mathrm{cfu} / \mathrm{g}$ was used. On vacuum packed sliced cooked ham, the concentration of $100 \mathrm{cfu} / \mathrm{g}$, the safety limit considered as low risk for causing listeriosis, was exceeded after 5 days whereas ca. $10^{5} \mathrm{cfu} / \mathrm{g}$ were obtained after 14 days when also LAB spoilers reached unacceptable numbers (ca. $10^{7} \mathrm{cfu} / \mathrm{g}$ ) whether standard or cold-adapted inoculum was used. The concentration of sodium lactate determined the opportunities for growth of L. monocytogenes in pâté. If growth of L. monocytogenes in pâté was noticed, the threshold of $100 \mathrm{cfu} / \mathrm{ml}$ was crossed earlier for the cold-adapted inoculum compared to the standard inoculum.

(c) 2003 Elsevier B.V. All rights reserved.
\end{abstract}

Keywords: Listeria monocytogenes; Challenge testing; Cooked meat products

\section{Introduction}

* Corresponding author. Tel.: +32-9-264-61-78; fax: +32-9225-55-10.

E-mail address: mieke.uyttendaele@UGent.be (M. Uyttendaele).
Listeria monocytogenes is commonly found in the environment, particularly in soil, decaying vegetation and as a part of the faecal flora of many 
animals. In addition, it is a psychrotrophic pathogen that can establish itself as a resident in the food processing environment (Farber and Peterkin, 1991). L. monocytogenes is frequently present in raw foods but can also be found as a result of post-contamination in cooked ready-to-eat (RTE) products such as cooked meat products. Pâté, jellied pork tongue and pork pâté "rilletes" were responsible for three major meat-related listeriosis epidemics in England and France (Goulet et al., 1993; Ryser, 1999). In a recent outbreak in northeast United States, precooked, sliced turkey deli meat was indicated as a causative agent resulting in seven deaths and three stillbirths (CDC, 2002). In general, there is a low incidence of L. monocytogenes in these types of meat products and several studies showed low or moderate levels of the pathogen being present (Farber and Peterkin, 1999). In the United States, overall incidences of the pathogen in cooked RTE meat products ranged from $0 \%$ to $8.1 \%$ (years 1993-1996) (Anonymous, 1997). A survey of cooked meat products in Germany showed an incidence rate of $3.7 \%$ for L. monocytogenes $(0.5 \%$ contained a high contamination level $(>10$ $\mathrm{cfu} / \mathrm{g})$ ) (Noack and Joeckel, 1993). In an extensive study in Yorkshire, cooked meats and paté revealed incidences of $5 \%$ and $7 \%$ for L. monocytogenes, respectively. Levels of the organism ranged from $<20$ to $1000 \mathrm{cfu} / \mathrm{g}$ (Anonymous, 1991). In a survey of cooked meat products on the Belgian retail market (3405 samples), the overall incidence of $L$. monocytogenes in $25 \mathrm{~g}$ was $4.90 \%$; however, only a small proportion $(0.53 \%)$ contained high contamination levels $(>10 \mathrm{cfu} / \mathrm{g})$. Higher incidence rates were obtained for whole cooked meat products (e.g., cooked ham, bacon) after slicing than before slicing, $6.65 \%$ and $1.56 \%$, respectively, indicating cross-contamination (Uyttendaele et al., 1999).

The prevalence of L. monocytogenes in cooked RTE meat products which may be consumed without further heating is obviously of concern, but as the levels of L. monocytogenes associated with contamination of these products are typically low, the risks are minimal if multiplication does not or cannot occur during storage, distribution and preparation. Epidemiologic data indicate that foods involved in listeriosis outbreaks are those in which the organism has multiplied and in general have contained levels significantly higher than $100 \mathrm{cfu} / \mathrm{g}$ (Buchanan et al.,1997; Ross et al., 2000; ICMSF, 2002). Based on risk assessment for $L$. monocytogenes in RTE foods, the Codex Alimentarius recommended that the maximum contamination level for L. monocytogenes in food at consumption should be less than 100/g (Codex Alimentarius, 2002). In order not to exceed these levels at the point of consumption, lower levels may need to be achieved at the production date for those foods in which growth can occur. However, the different types of cooked RTE meat products rely on food preservation by combined processes (Leistner, 2000) for which the issue of whether L. monocytogenes can grow in these food products is difficult to answer. When it is not known whether L. monocytogenes can multiply in the product under the prevailing conditions of storage and distribution, or how rapidly they can multiply, it is recommended to acquire experimental data concerning the implicated product (Codex Alimentarius, 2002; European Commission, 2000). This can be accomplished by repeated shelf life studies on products found positive for $L$. monocytogenes, or if naturally contaminated material is not available, challenge testing should be performed. In the frame of the food safety objective set by the WHO/FAO (Codex Alimentarius, 2002) and referring to a Draft European Commission Proposal on the control of L. monocytogenes in RTE foods (European Commission, 2000) to set a limit of 100 L. monocytogenes per gram, challenge testing will become an important tool to document the stability of the implicated RTE food towards growth of L. monocytogenes. Although recommendations considering the performance of challenge testing are available (Rose and Stringer, 1987; Notermans and in't Veld, 1994) and indicate the critical factors to consider in designing a challenge test, e.g. choice of test strain, preparation of the inoculum and inoculum level, inoculation procedure, these are not detailed enough. Thus at present, there is uncertainty about the approach and scope for a multiplicity of ad hoc testing of the ability of $L$. monocytogenes to multiply in foods. These tests are liable to be of varied design and may in some cases be of uncertain value (Lund, 2000). The present study was undertaken to evaluate a protocol for challenge testing. It was applied to RTE cooked meat products obtained from a local production site. The outcome of a 
varied design on the outcome of the challenge testing was evaluated. Particularly the choice of the strain and the effect of the previous growth temperature was documented.

\section{Materials and methods}

\subsection{Bacterial strains and preparation of inoculum}

Seven clinical strains and seven food isolates of $L$. monocytogenes (Table 1) obtained from the Scientific Institute of Public Health-Louis Pasteur, Brussels, Belgium, were included in the study. As a reference strain, Scott A present in the culture collection of the Laboratory of Food Microbiology and Food Preservation, University of Gent, Belgium, was used. Stock cultures of the strains were maintained on Tryptone Soya Agar (TSA, Oxoid, Basingstoke, England) slants at $7{ }^{\circ} \mathrm{C}$ and revived by transferring a loop inoculum into $10 \mathrm{ml}$ Brain Heart Infusion broth (BHI, Oxoid) or $10 \mathrm{ml}$ Tryptone Soya Broth (TSB, Oxoid) followed by incubation at $30{ }^{\circ} \mathrm{C}$ for $24 \mathrm{~h}$.

\subsection{Microbiological culture media}

In different stages of the study, various microbiological culture media were used, namely Peptone

Table 1

Overview of L. monocytogenes strains implicated in the study

\begin{tabular}{ll}
\hline Strain & Origin $^{\mathrm{a}}$ \\
\hline 2000/097 serotype $1 / 2 \mathrm{a}$ & Clinical \\
2000/017 serotype $1 / 2 \mathrm{~b}$ & Clinical \\
2000/048 serotype $1 / 2 \mathrm{c}$ & Clinical \\
2000/096 serotype $4 \mathrm{~b}$ & Clinical \\
2000/080 serotype $4 \mathrm{~b}$ & Clinical \\
2000/074 serotype $4 \mathrm{~b}$ & Clinical \\
2000/014 serotype $4 \mathrm{~b}$ & Clinical \\
Scott A & Clinical \\
2000/099 serotype $1 / 2 \mathrm{a}$ & Food (ground beef) \\
2000/098/04 serotype $1 / 2 \mathrm{~b}$ & Food (ground beef) \\
2000/098/02 serotype $1 / 2 \mathrm{c}$ & Food (ground beef) \\
2000/101 serotype $4 \mathrm{~b}$ & Food (cooked ham) \\
2000/094 serotype $4 \mathrm{~b}$ & Food (poultry meat) \\
2000/087/02 serotype $4 \mathrm{~b}$ & Food (cooked ham) \\
2000/071/02 serotype $4 \mathrm{~b}$ & Food (pate) \\
\hline
\end{tabular}

\footnotetext{
${ }^{a}$ Obtained from the Scientific Institute of Public Health-Louis
} Pasteur, Brussels, Belgium.
Physiological Salt solution (PPS; 8.5 g/l NaCl (VWS, Leuven, Belgium) and $1 \mathrm{~g} / \mathrm{l}$ Peptone (Oxoid)) for preparation of dilution serials; Nutrient Agar (NA, Oxoid) or TSA as nonselective media for enumeration of pure cultures of L. monocytogenes (incubation for $24-48 \mathrm{~h}$ at $30{ }^{\circ} \mathrm{C}$ ); ALOA (Biolife, Milan, Italy) (incubation for $24-48 \mathrm{~h}$ at $37{ }^{\circ} \mathrm{C}$ ) as a selective medium for enumeration or isolation of L. monocytogenes from food samples; de Man Rogosa Sharpe agar (MRS, Oxoid) (micro-aerophilic incubation for $72 \mathrm{~h}$ at $30{ }^{\circ} \mathrm{C}$ ) for enumeration of lactic acid bacteria in food samples; demi-Fraser broth (Oxoid) incubated for $24 \mathrm{~h}$ at $30{ }^{\circ} \mathrm{C}$ and Fraser broth (Oxoid) incubated for $24 \mathrm{~h}$ at $37{ }^{\circ} \mathrm{C}$ for selective enrichment of L. monocytogenes; and Listeria Selective Agar (Oxford formulation) (Oxford, Oxoïd) as recommended in the protocol of Bolton and Frank (1999) to study the acid-adaptive response of L. monocytogenes.

\subsection{Characterisation of L. monocytogenes strains}

Initially, the variability of the response of the $L$. monocytogenes strains mentioned in Table 1 to different stress and growth conditions was studied in order to choose a L. monocytogenes strain with a representative behaviour for the pathogen. The resistance of L. monocytogenes towards acid and the acid tolerance response was determined as described by Bolton and Frank (1999) for all of the above mentioned L. monocytogenes strains. In short, appropriate dilutions of both unadapted (24-h TSB culture) and acid-adapted cells (a 24-h TSB culture subjected to 3$\mathrm{h}$ incubation at $30{ }^{\circ} \mathrm{C}$ in acidified TSB $(\mathrm{pH} 5.0$ adjusted with $2 \mathrm{ml} / 1$ 85\% lactic acid (Sigma, St. Louis, $\mathrm{MO}$ ) resulting in a concentration of $0.12 \mathrm{ml} / 1$ undissociated lactic acid) were plated (in duplicate) on Oxford and Oxford acidified to $\mathrm{pH} 5.25$ with $1.1 \mathrm{ml} / 185 \%$ lactic acid (a-Oxford) resulting in a concentration of undissociated lactic acid of $0.036 \mathrm{ml} / 1$ and incubated at $37{ }^{\circ} \mathrm{C}$ for $24 \mathrm{~h}$ (Oxford plates) and $60 \mathrm{~h}$ (a-Oxford plates) to detect acid adaptation. An adaptive response is shown by production of large $(>1 \mathrm{~mm})$ colonies on a-Oxford.

For a selection of the L. monocytogenes strains (2000/099, 2000/097 and 2000/071/02 and Scott A), the acid tolerance response was determined as described by Gahan et al. (1996). In this method, 
the survival of unadapted cells (24-h culture in TSB ( $\mathrm{pH}$ 7.0) supplemented with $0.6 \%$ Yeast Extract (YE, Oxoid) and acid-adapted cells (a 24-h TSBYE (pH 7.0) culture subjected to 60-min incubation at $37{ }^{\circ} \mathrm{C}$ in acidified TSB-YE (pH 5.5)) was determined in TSB-YE acidified to $\mathrm{pH} 3.5$ with 3 $\mathrm{M}$ lactic acid. Viable plate counts were performed at 30-min intervals for up to $120 \mathrm{~min}$ at $37{ }^{\circ} \mathrm{C}$ by serial dilution of samples in PPS and plating on TSA plates. For each strain, the experiment was performed in duplicate.

Subsequently, the behaviour of a selection of the $L$. monocytogenes strains (2000/097; 2000/017; 2000/ 048; 2000/014; 2000/074; Scott A; 2000/099; 2000/ 098/04; 2000/098/02; 2000/094; 2000/101/03) was determined in four different combined stress conditions. Combinations were as shown in Table 2. One milliliter of an appropriate dilution of a 24-h BHI culture was transferred into $20 \mathrm{ml}$ BHI with $\mathrm{pH}$ adjusted (using $1 \mathrm{~N} \mathrm{HCl}$ (VWR, Leuven)), and supplemented with $\mathrm{NaCl}$ and sodium lactate (VWR, Leuven) in order to obtain the concentrations and $a_{\mathrm{w}}$ values as mentioned in Table 2 (final inoculum ca. $10^{4}$ $\mathrm{cfu} / \mathrm{ml})$. The $\mathrm{pH}$ and $a_{\mathrm{w}}$ values were confirmed by measurement of $\mathrm{pH}$ using an Ingold electrode (MGDX K57, Urdorf, Switzerland) connected to a pH meter (type 763, Knickn, Berlin, Germany) and of water activity using an $a_{\mathrm{w}}$ cryometer (Nagy AWK-20, Gäufelden, Germany). For each L. monocytogenes strain, the inoculation was performed in duplicate. Incubation was performed at temperatures indicated in the Table 2 for a prolonged time period ( 20 days for test conditions 1 and 2, 28 days for test condition 3, and 13 days for test condition 4). Growth of the $L$. monocytogenes strains was determined by plating on TSA on regular time intervals. For test conditions 1 and 2, the test results were subjected to nonlinear regression [(Baranyi and Roberts, 1994)] in SPSS
10.0.0 (SPSS, Chicago, IL, USA) to determine the lag phase $(\lambda)$ and maximum specific growth rate $\left(\mu_{\max }\right)$.

\subsection{Effect of choice of strain and history of the strain} on growth of L. monocytogenes under conditions of cooked ham and pate using optical density measurements $(O D)$ in microtitre plates

Four strains, two clinical (2000/097 and Scott A) and two food strains (2000/099 and 2000/071/02), were tested individually to document the behaviour of the individual strains. Inoculum was prepared either by incubation in TSB for $24 \mathrm{~h}$ at $30{ }^{\circ} \mathrm{C}$ (standard inoculum) or by incubation in TSB for 7 days at $7{ }^{\circ} \mathrm{C}$ (cold-adapted inoculum) in order to determine the effect of the pre-incubation temperature on the subsequent growth of the strain at $7{ }^{\circ} \mathrm{C}$. A low inoculum level was preferred. To determine the growth parameters $\lambda$ and $\mu_{\max }$, the following experimental setup was used. The inoculum was standardised at $10^{9} \mathrm{cfu} /$ $\mathrm{ml}$ using a calibration curve that describes the relationship between optical density at $600 \mathrm{~nm}$ and the cell density. Subsequently, the inoculum (standard and cold-adapted) was serially diluted (10-fold dilutions) in the respective growth medium to obtain ca. $10^{4} \mathrm{cfu} /$ $\mathrm{ml}$ (exact inoculum was verified by enumeration on TSA). From the latter, $200 \mu 1$ was added to the first column (eight wells) of a microtitre plate of which all wells were filled with $200 \mu$ l of either BHI or modified BHI simulating the conditions of either cooked ham (BHI adjusted to $\mathrm{pH} 6.2$ with $1.2 \mathrm{ml}$ $85 \%$ lactic acid per liter (limiting the concentration of undissociated lactic acid to $0.0046 \mathrm{ml} / \mathrm{l}$ ) and to $a_{\mathrm{w}}$ 0.972 with $\mathrm{NaCl}$ ) or paté (BHI adjusted to $\mathrm{pH} 6.1$ with $1.2 \mathrm{ml} 85 \%$ lactic acid per liter and to $a_{\mathrm{w}} 0.957$ with $\mathrm{NaCl}$ ). The $\mathrm{pH}$ and $a_{\mathrm{w}}$ value of the modified BHI were confirmed by measurement as mentioned above.

Table 2

Combined stress conditions used to determine growth variations of L. monocytogenes strains

\begin{tabular}{lllllc}
\hline & $\begin{array}{l}\text { Temperature } \\
\left({ }^{\circ} \mathrm{C}\right)\end{array}$ & $\mathrm{pH}$ & $a_{\mathrm{w}}$ & $\begin{array}{l}\mathrm{NaCl} \\
(\mathrm{w} / \mathrm{v}, \%)\end{array}$ & $\begin{array}{l}\text { Sodium lactate } \\
(\mathrm{w} / \mathrm{v}, \%)\end{array}$ \\
\hline Condition 1 & 4 & 5.5 & 0.977 & 4.0 & $-{ }^{\mathrm{a}}$ \\
Condition 2 & 7 & 6.0 & 0.960 & 7.5 & - \\
Condition 3 & 7 & 5.0 & 0.985 & 2.1 & 1.0 \\
Condition 4 & 7 & 6.2 & 0.974 & 3.0 & 3.0 \\
\hline
\end{tabular}

\footnotetext{
${ }^{\mathrm{a}}$ Not added.
} 
This procedure resulted in approximately 2000 cells/ well of the first row of the microtitre plate, which can be used to make twofold dilutions in the subsequent rows (subsequently transfer $200 \mu \mathrm{l}$ to $200 \mu \mathrm{l}$ fresh broth in the wells of the adjacent row, etc. and finally remove $200 \mu \mathrm{l}$ from the last row of the microtitre plate) in order to obtain in each row an inoculum level of ca. 1000-500-250-120-60-30 cells/well. For paté conditions, the experiment was also performed with a higher inoculum level ranging from ca. $10^{7}$ to $10^{5} \mathrm{cfu} /$ $\mathrm{ml}$. For each inoculum level, 24 replicates were prepared. Microtitre plates were incubated for a prolonged time period at $7{ }^{\circ} \mathrm{C}$ and at regular time intervals the optical density (OD) of the wells was measured at $600 \mathrm{~nm}$ using a Versamax (Molecular Devices, Sunnyvale, CA, USA) absorbance reader. Software used to analyse test results was Softmax ${ }^{\circledR}$ PRO 4.0 (Molecular Devices) and Microsoft ${ }^{\circledR}$ Excel 2000 (Microsoft, Redmond, WA, USA). The methodology used was similar as described by Francois et al. (2003).

\subsection{Microbial challenge testing (MCT) of L. mono- cytogenes in modified atmosphere packaged (MAP) sliced cooked ham and paté}

A challenge testing protocol is proposed and evaluated on two types of RTE cooked meat products. Retail packs of vacuum packed sliced cooked ham and modified atmosphere packed paté were obtained from a local production site at the day of production (day 0) and kept at $7{ }^{\circ} \mathrm{C}$ for maximum $4 \mathrm{~h}$ until the event of inoculation. The shelf life of the cooked ham and the pate as given by the producer was 28 and 19 days, respectively. At arrival, the gas composition was determined using a $\mathrm{CO}_{2} / \mathrm{O}_{2}$ gas analyser (Servomex Food Package Analyzer Series 1450 CISMA, Zoetermeer, The Netherlands) in order to be able to repack the cooked meat products after inoculation under the original atmosphere.

The option was taken to use a mixed inoculum of four L. monocytogenes strains, two clinical (2000/097 and Scott A 3955) and two food (2000/099 and 2000/ 071/02) strains, in order to confer greater confidence in the assessment of the likelihood of a particular strain to compromise food safety. In order to determine the influence of the pre-incubation temperature on subsequent growth of the L. monocytogenes in the challenge test, all four strains were revived by both incubation for $24 \mathrm{~h}$ at $30{ }^{\circ} \mathrm{C}$ (standard inoculum) and incubation for 7 days at $7{ }^{\circ} \mathrm{C}$ (cold-adapted inoculum). Subsequently, the inoculum (a standard inoculum and a cold-adapted inoculum) was prepared by serial dilution in PPS of the individual strains and combining $2 \mathrm{ml}$ of the appropriate dilution containing ca. $10^{3} \mathrm{cfu} / \mathrm{ml}$ of each strain in a sterile empty tube. These mixtures served as an inoculum for the challenge test. The exact inoculum concentration was determined by enumeration on TSA.

Surface inoculation of one slice of cooked ham (ca. $50 \mathrm{~g}$ (five slices in a retail pack)) and a 50-g portion of paté $(1 / 3$ of a $150-\mathrm{g}$ thick slice in a retail pack) was performed by disposal of $100 \mu \mathrm{l}$ of the mixed inoculum with a micro-pipette on the slice and spreading over the surface with a sterile disposable plastic spatula in order to obtain an inoculum of ca. $1-10 \mathrm{cfu} / \mathrm{g}$. A low inoculum level $(<10 \mathrm{cfu} / \mathrm{g}$ ) was chosen being realistic according to the data available on the contamination level of RTE cooked meat products with L. monocytogenes (Uyttendaele et al., 1999). Inoculation was performed at room temperature in an aseptic way under the flow of a biohazard (Holten LaminAir, Alleroed, Denmark). Within $15 \mathrm{~min}$ after inoculation, portions of two inoculated cooked ham slices (one partially covering the other with no contact between two inoculated sides) were vacuum packed. Portions of paté (one thick slice) was packed under modified atmosphere $\left(30 \% \mathrm{CO}_{2} / 70 \% \mathrm{~N}_{2}\right)$. Packaging was performed using a Multivac A300/42 (Hagenmüller, Wolfertschwenden, Germany) gas packaging machine combined with a gas mixer (WITT MG18-3MSO, Goreteknik, Germany) in a high barrier film (NX90, Euralpak, Wommelgem, Belgium) of $90 \mu \mathrm{m}$ thickness with an oxygen transmission rate of $2.0 \mathrm{ml} / \mathrm{m}^{2} 24 \mathrm{~h}$ atm and a carbon dioxide transmission rate of $5.2 \mathrm{ml} / \mathrm{m}^{2} 24$ $\mathrm{h}$ atm. Portions were immediately after packaging put at $7{ }^{\circ} \mathrm{C}$ in a ventilated refrigerator. In total, $14 \mathrm{~L}$. monocytogenes inoculated packages were made for each food product representing duplicate serials of seven packages each. Some control non-inoculated packages were also prepared. At day 0 and at regular time intervals during the shelf life, duplicate samples were taken and microbiological analyses were performed. Test samples were analysed for the presence of L. monocytogenes both quantitatively (enumera- 
tion on ALOA) and qualitatively. For the latter, primary enrichment of both $10 \mathrm{ml}$ (corresponding to $1 \mathrm{~g}$ ) of a 10-fold diluted homogenized $25 \mathrm{~g}$ sample in demi-Fraser broth and the remaining 240 $\mathrm{ml}$ demi-Fraser broth suspension (corresponding to $24 \mathrm{~g})$ was performed. Subsequently, $0.1 \mathrm{ml}$ of incubated demi-Fraser broth was transferred to 10 $\mathrm{ml}$ Fraser broth for secondary enrichment and, finally, isolation on ALOA. As L. monocytogenes produce typical colonies on ALOA (Vlaemynck et al., 2000) and as no typical colonies were noticed on ALOA plates from non-inoculated control samples, no confirmation of typical colonies was performed. The presence of lactic acid bacteria (enumeration on MRS) was also followed up during shelf life. Measurements of $\mathrm{pH}$ using an Ingold electrode (MGDX K57, Urdorf) connected to a $\mathrm{pH}$ meter (type 763, Knickn) and of water activity using an $a_{\mathrm{w}}$ cryometer (Nagy AWK-20) was performed during the shelf life using non-inoculated samples.

In order to establish variations in the outcome of the challenge test due to slight differences in the intrinsic, extrinsic and implicit factors of the RTE cooked meat product, the experiment was three times repeated with pre-packed sliced cooked ham and paté from different production dates. The second experiment was deviating from the other two experiments (1) in terms of chilling the retail packs of cooked ham and pâté prior and immediately after the inoculation at a temperature close to $0{ }^{\circ} \mathrm{C}$ for three $\mathrm{h}$ and (2) in cooling and adjusting the PPS used for the dilution serials during preparation of the inoculum to a temperature of $7{ }^{\circ} \mathrm{C}$ and $\mathrm{pH}$ and $a_{\mathrm{w}}$ values corresponding to the values of the cooked meat product to be inoculated. This in order to prevent rapid temperature rise or local modification of the $\mathrm{pH}$ and $a_{\mathrm{w}}$ and creating opportunities for growth of $L$. monocytogenes during the inoculation procedure.

\section{Results}

\subsection{Characterisation of L. monocytogenes strains: acid adaptation}

Using the simple method described by Bolton and Frank (1999), it was noticed that all the food isolates of L. monocytogenes except strain 101/03 grew well in acid conditions (Oxford at $\mathrm{pH}$ 5.25), thus indicating that these strains are intrinsically acid resistant. Colonies observed on acidified Oxford were even bigger than on Oxford but this may be explained by the prolonged incubation time (60 $\mathrm{h}$ compared to $24 \mathrm{~h}$ ). On the contrary, strain 101/03 as well as the Scott A reference strain and one of the clinical strains $(2000 / 096)$ did not adapt to the acid environment. Both the unadapted and acidadapted cells of these strains grew well on Oxford but produced extremely small pin point colonies on acidified Oxford. One clinical strain (strain 2000/ 014) needed acid adaptation to grow to big colonies on acidified Oxford. For the remaining clinical strains, both the unadapted and acid-adapted colonies showed normal colonies on both Oxford and acidified Oxford (although largest colonies were observed on Oxford). Thus, adaptation was not required to grow well on acidified Oxford. The acid adaptive response was further studied for four strains, two clinical strains (reference strain Scott A serotype $4 \mathrm{~b}, 2000 / 097$ serotype $1 / 2 \mathrm{a}$ ) and two food isolates $(2000 / 071 / 02$ serotype $4 b, 2000 / 099$ serotype $1 / 2 \mathrm{a}$ ) by follow up of the survival of both unadapted and acid-adapted cells in an acid $(\mathrm{pH}$ 3.5) minimal medium as described by Gahan et al. (1996). Under these conditions, all four implicated L. monocytogenes strains showed resistance towards the challenge $\mathrm{pH}(\mathrm{pH} 3.5)$ after adaptation. Adapted cells showed less than $1 \log$ decrease in the 120min incubation time whereas the unadapted cells decreased nearly 4 (the serotype $1 / 2 \mathrm{a}$ strains) to nearly 5-6 log units (the serotype $4 \mathrm{~b}$ strains) in the same time period (Fig. 1). In fact, it was noted that adapted cells of Scott A showed an acid tolerance response in the latter experiment and that the unadapted cells of the other three L. monocytogenes strains were acid-sensitive whereas they were not in the simplified test by Bolton and Frank (1999). This might be ascribed to the difference in challenge $\mathrm{pH}$ being more extreme $(\mathrm{pH}$ 3.5) in the method of Gahan et al. (1996) whereas a moderate acid $\mathrm{pH}$ $(\mathrm{pH}$ 5.25) resembling more the $\mathrm{pH}$ in acid foods was used in the method by Bolton and Frank (1999).

From the test results, it can be concluded that all L. monocytogenes, even if not acid-adapted, are able to multiply and develop colonies (although pin point 


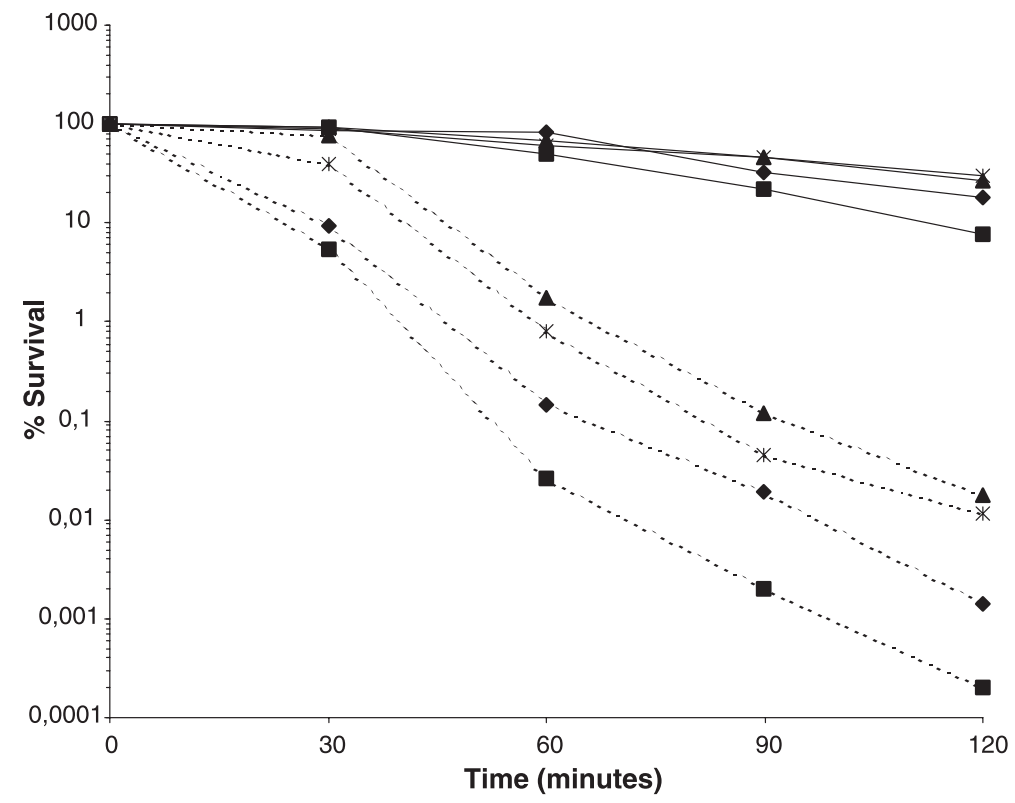

Fig. 1. Acid tolerance response in L. monocytogenes. The survival of acid-adapted (-) and nonadapted (- - -) L. monocytogenes strains

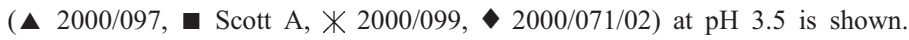

colonies for 3 out of 15 strains) under moderate acid $\mathrm{pH}$ (5.25). The four strains tested in particular behaved similarly and showed an acid-adaptive response.

\subsection{Characterisation of L. monocytogenes strains: response to suboptimal growth conditions}

The behaviour of six clinical strains and five food isolates was determined under different stress conditions. Growth curves are shown in Fig. 2. To substantiate quantitatively the observations made with regard to variation in the behaviour of the $L$. monocytogenes strains under different stress conditions as noticed in Fig. 2, the lag phase $(\lambda)$ and maximum specific growth rate $\left(\mu_{\max }\right)$ of the $L$. monocytogenes strains were calculated by nonlinear regression (Baranyi and Roberts, 1994) for conditions 1 and 2 (Table 3 ). In condition 1 , the clinical strains 2000/097 and Scott A showed a short lag phase but also a low maximum specific growth rate whereas the clinical strain 2000/074 as well as the two of the five food isolates (2000/094 and 2000/ 101/03) showed a long lag phase but a high specific maximum growth rate. Low maximum numbers were reached for strain 2000/074 and 2000/101/03. In condition 2, the clinical strain 2000/097 also showed a short lag phase and a low maximum specific growth rate. A long lag phase was noted for clinical strain 2000/048 and rapid growth was observed for Scott A in condition 2 as well as for the food isolates 2000/094 and 2000/101/03. In condition 3, all L. monocytogenes strains survived but no growth was noticed in the 4 weeks the experiment was conducted. In condition 4, rapid growth of L. monocytogenes was noticed. Taking into account the test results of all four conditions there was not one L. monocytogenes strain which had consistently significant longer or shorter lag phase or higher or lower maximum specific growth rates.

3.3. Effect of choice of strain and history of the strain on growth of L. monocytogenes under conditions of cooked ham and paté using optical density measurements (OD) in microtitre plates

From the L. monocytogenes strains mentioned in Table 1, four strains (Scott A, 2000/097, 2000/099, $2000 / 071 / 02$ ) were selected to be used in a mixed 

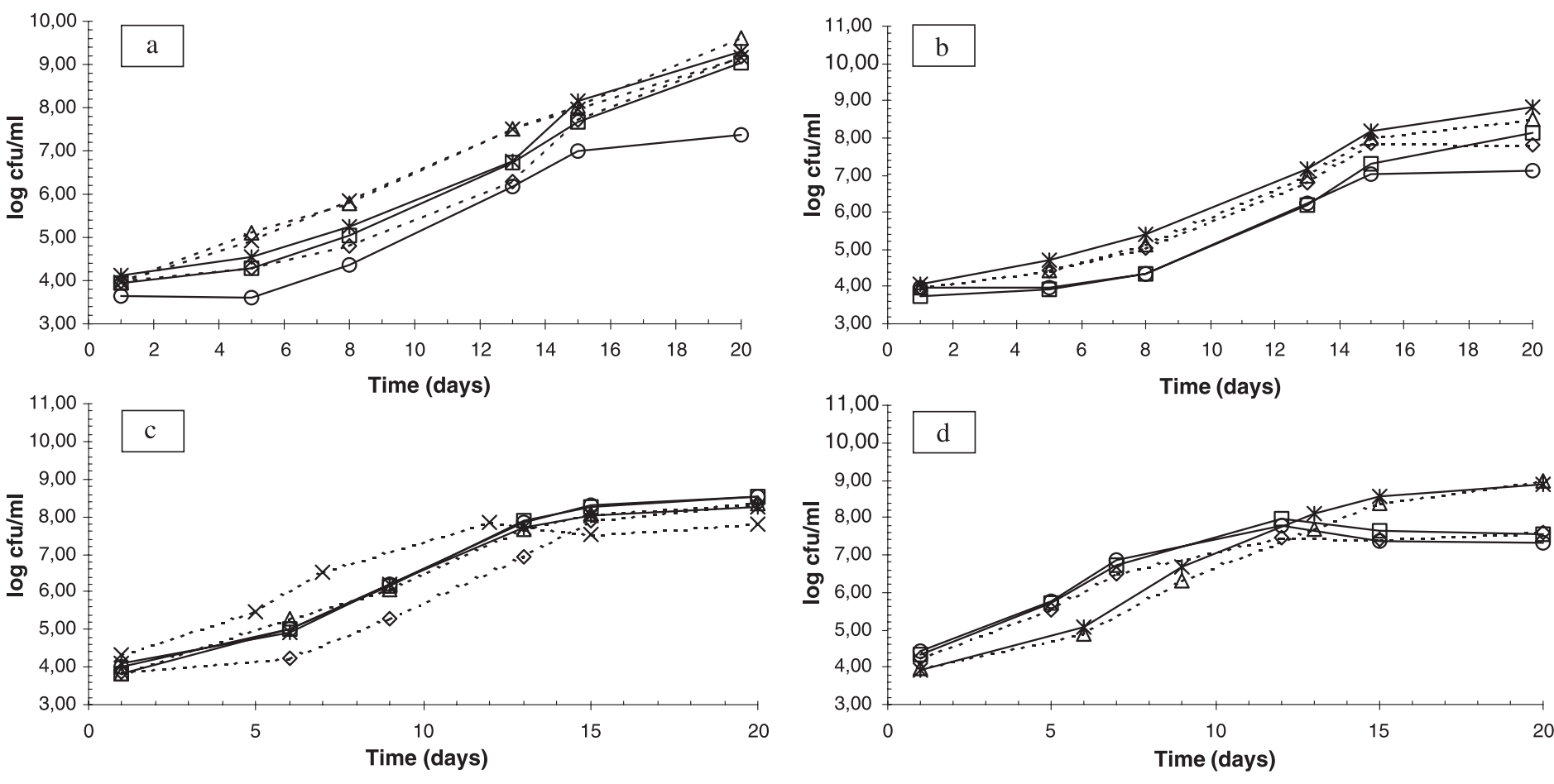

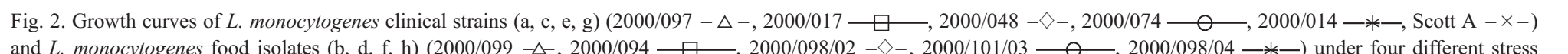
and $L$. monocytogenes food isolates $(\mathrm{b}, \mathrm{d}, \mathrm{f}, \mathrm{h})\left(2000 / 099-\triangle\right.$, , 2000/094 $\left.\square-, 2000 / 098 / 02-\nabla_{-}, 2000 / 101 / 03-\square-, 2000 / 098 / 04 \longrightarrow *-\right)$ under four different stress conditions: condition 1 (a, b): $\mathrm{pH} 5.5, a_{\mathrm{w}} 0.977,4{ }^{\circ} \mathrm{C}$; condition 2 (c, d): $\mathrm{pH} 6.0, a_{\mathrm{w}} 0.955,7{ }^{\circ} \mathrm{C}$; condition 3 (e, f): $\mathrm{pH} 5.0, a_{\mathrm{w}} 0.958,7{ }^{\circ} \mathrm{C} ;$ condition 4 (g, h): $\mathrm{pH} 6.2, a_{\mathrm{w}} 0.969,7{ }^{\circ} \mathrm{C}$. 


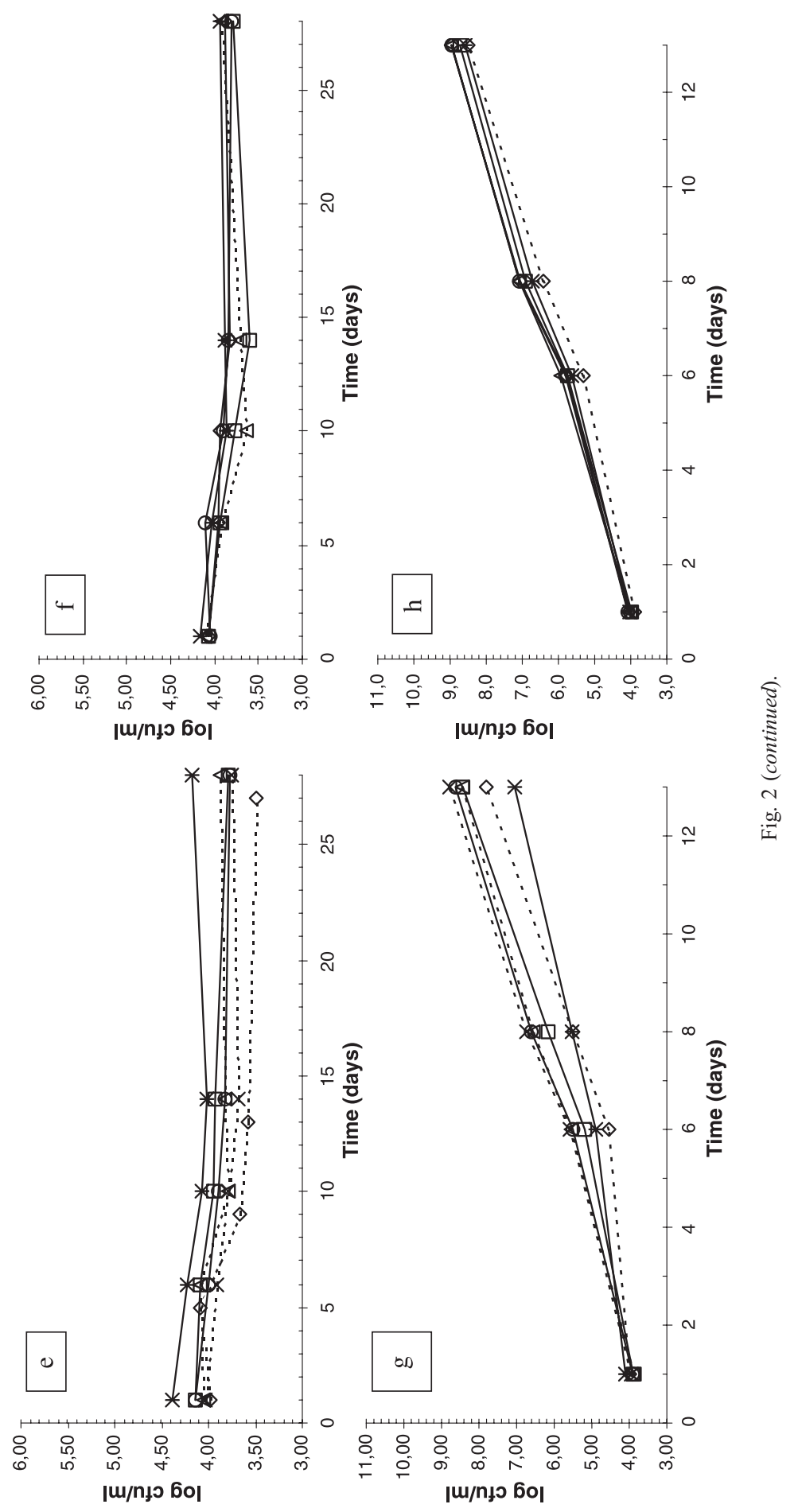


Table 3

Growth parameters (lag phase $(\lambda)$ in days, maximum specific growth rate $\left(\mu_{\max }\right)$ in days ${ }^{-1}$ ) of the $L$. monocytogenes strains under stress conditions calculated by nonlinear regression (Baranyi and Roberts, 1994)

\begin{tabular}{|c|c|c|c|c|}
\hline \multirow[t]{2}{*}{ Strain } & \multicolumn{2}{|c|}{$\begin{array}{l}\text { Condition } 1, \mathrm{pH} 5.5 \text {, } \\
a_{\mathrm{w}} 0.977,4{ }^{\circ} \mathrm{C} \\
\end{array}$} & \multicolumn{2}{|c|}{$\begin{array}{l}\text { Condition } 2, \mathrm{pH} 6.0, \\
a_{\mathrm{w}} 0.955,7{ }^{\circ} \mathrm{C} \\
\end{array}$} \\
\hline & $\lambda$ & $\mu_{\max }$ & $\lambda$ & $\mu_{\max }$ \\
\hline $2000 / 097$ & 1.3 & 0.31 & 3.1 & 0.44 \\
\hline $2000 / 017$ & 5.0 & 0.36 & 4.5 & 0.55 \\
\hline $2000 / 048$ & 6.8 & 0.41 & 7.0 & 0.58 \\
\hline $2000 / 014$ & 6.8 & 0.47 & 5.3 & 0.58 \\
\hline $2000 / 074$ & 7.9 & 0.58 & 4.9 & 0.56 \\
\hline Scott A & 2.2 & 0.35 & 3.8 & 0.78 \\
\hline $2000 / 099$ & 6.5 & 0.51 & 4.3 & 0.49 \\
\hline $2000 / 098 / 04$ & 5.6 & 0.46 & 4.1 & 0.57 \\
\hline $2000 / 098 / 02$ & 6.8 & 0.55 & 3.2 & 0.71 \\
\hline $2000 / 094$ & 8.7 & 0.60 & 3.4 & 0.79 \\
\hline $2000 / 101 / 03$ & 9.2 & 0.73 & 3.6 & 0.93 \\
\hline $\begin{array}{l}\text { Mean value } \\
\pm 95 \% \\
\text { confidence } \\
\text { interval }\end{array}$ & $6.1 \pm 1.5$ & $0.48 \pm 0.07$ & $4.3 \pm 0.7$ & $0.63 \pm 0.09$ \\
\hline
\end{tabular}

culture for challenge testing. The option was taken to include two clinical strains and two food isolates compromising two serotype $4 \mathrm{~b}$ and two serotype 1/ 2a strains. Initially, the growth characteristics of each individual strain at $7{ }^{\circ} \mathrm{C}$ were determined in $\mathrm{BHI}$ and modified BHI simulating the conditions of either cooked ham or paté using a low inoculum level (twofold dilutions ranging from ca. 1000 to 30 $\mathrm{cfu} / \mathrm{ml}$ ) and a pre-incubation temperature of the inoculum of $7{ }^{\circ} \mathrm{C}$ (cold-adapted) or $30{ }^{\circ} \mathrm{C}$ (standard). Growth curves obtained for one of the test strains (2000/099) are shown in Fig. 3 (each data point is the mean of 24 replicates). No growth of the L. monocytogenes strains was observed for the BHI adjusted to pâté conditions after 21 days when a low inoculum level was used. It was established that under more severe stress conditions none of the cultures grew when the inoculum size was too low (less than $10^{3}$ cells) whereas growth is noted with a higher inoculum (Robinson et al., 2001; Pascual et al., 2001). The experiment for the BHI adjusted to pâté conditions was repeated with a high inoculum level $\left(10^{7}-10^{5} \mathrm{cfu} / \mathrm{ml}\right)$ and these results are shown in Fig. 3. For each combination of pre-incubation temperature and modified BHI, the growth curves of six subsequent twofold dilutions are obtained. It is assumed that the maximum specific growth rate is independent of the inoculum size (Robinson et al., 2001). This is also confirmed in the present experiment. The slope of the straight line fit to the data points in the exponential phase, being similar for the highest and lowest inoculum level of the twofold dilution serial, confirms this assumption. The difference in detection times between consecutive dilutions should be constant provided that there is no effect of inoculum size on population lag times. It was shown that cultures inoculated with stationary phase cells (as in the present experiment) showed a linear relationship between inoculum size and detection time, except at very low numbers (less than 40 cells) (Robinson et al., 2001). In the present experiment, the theoretical difference in time to detection for two subsequent inoculum levels is in theory one generation time. In order to cover for some experimental variation in difference in detection times between two consecutive dilutions, in the present experiment, the generation time (GT) was calculated as the difference in time to detection at an established OD in the exponential phase between the highest and lowest inoculum level divided by five (five consecutive twofold dilutions difference). With the knowledge of the initial inoculum level (determined by enumeration on TSA) and the calculated GT, the lag phase of the L. monocytogenes strain under the applied pre-incubation temperature and modified BHI combination could be determined (Table 4). From Table 4, it can be noticed that in general all four L. monocytogenes strains behave similarly. Only strain 2000/097 in BHI and BHI adjusted to ham conditions and Scott $\mathrm{A}$ in BHI adjusted to pâté conditions showed a longer lag phase if pre-incubated at $30{ }^{\circ} \mathrm{C}$. As expected, BHI adjusted to pâté conditions (lowest $\mathrm{pH}$ and $a_{\mathrm{w}}$ ) is the most inhibitory to growth of L. monocytogenes (longest GT); nevertheless, the lag phase in pâté conditions were shorter than the corresponding lag times noted for ham conditions. It was shown that there is not necessarily a good correlation between lag time and mean generation time (Robinson et al., 1998). It is noticed that the GT is independent of the pre-incubation temperature as it is normally also assumed. In standard BHI, no difference in lag phase is observed for the cold-adapted and standard inoculum, whereas in BHI adjusted to ham condi- 

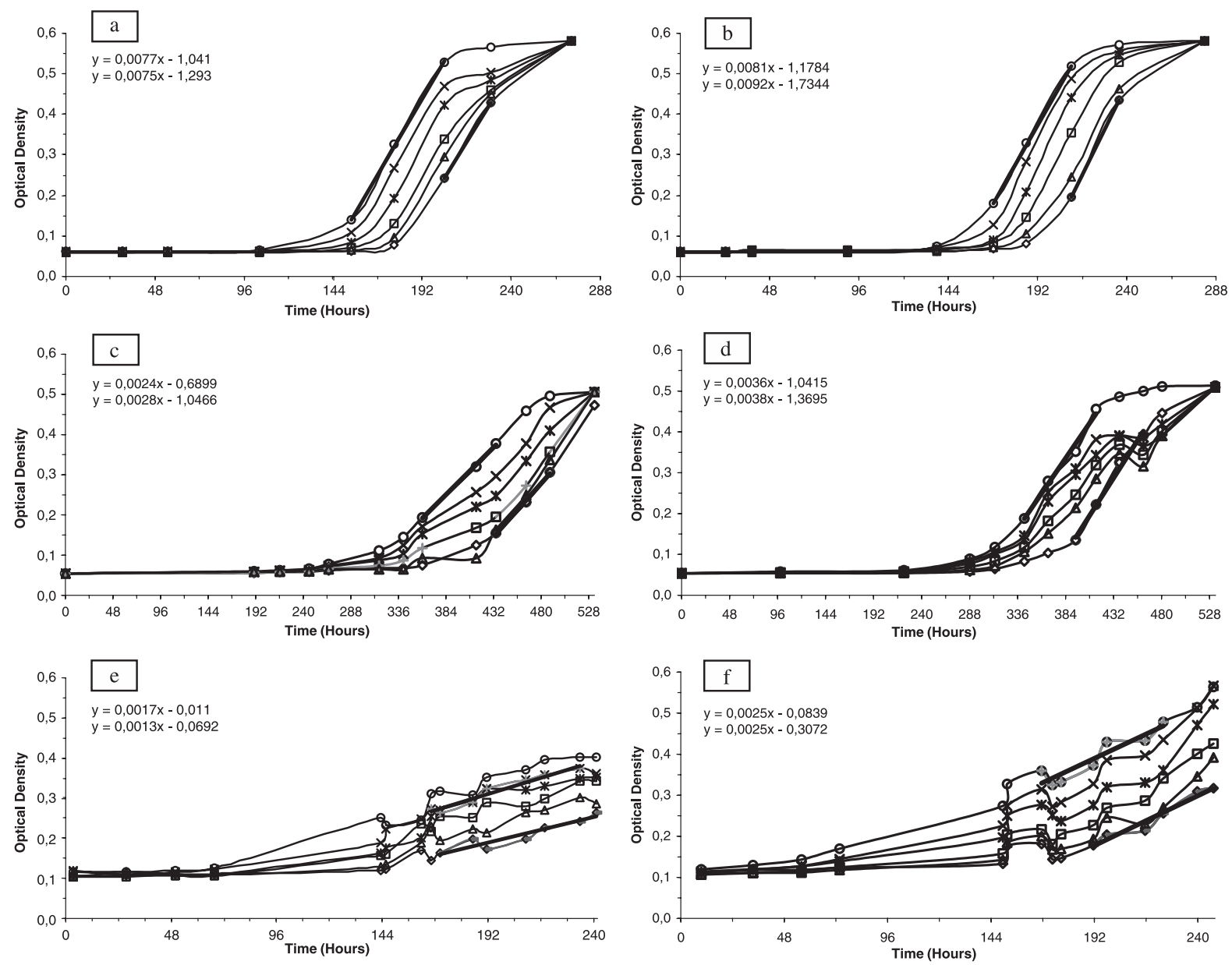

Fig. 3. Growth curves of L. monocytogenes strain $2000 / 099$ (pre-incubated at either $30{ }^{\circ} \mathrm{C}(\mathrm{a}, \mathrm{c}, \mathrm{e})$ or $7{ }^{\circ} \mathrm{C}$ (b, d, f)) in BHI (a, b), BHI adjusted to ham conditions (c, d) ( $\mathrm{pH} 6.2$ (with lactic acid), $a_{\mathrm{w}}$ 0.972) and BHI adjusted to paté conditions (e, f) (pH 6.1 (with lactic acid), $a_{\mathrm{w}} 0.957$ ) incubated at $7{ }^{\circ} \mathrm{C}$. Inoculum levels implicated were $1000(\mathrm{O}), 500(\times), 250 \%, 120(\square), 60(\triangle)$ and $30(\diamond) \mathrm{cfu} / \mathrm{ml}$ for BHI and BHI adjusted to ham conditions and similarly twofold dilutions starting from $10^{7} \mathrm{cfu} / \mathrm{ml}$ for BHI adjusted to pâté conditions.

tions as well as in BHI adjusted to pâté conditions, a ca. $40 \mathrm{~h}$ reduction of the lag phase is noted for the cold-adapted inoculum in comparison to the standard inoculum.

\subsection{Microbial challenge testing (MCT) of L. mono-} cytogenes in modified atmosphere packaged (MAP) sliced cooked ham and paté

In order to obtain more information about the effect of pre-incubation temperature on the subsequent growth of L. monocytogenes in microbial challenge testing, surface inoculation of a cold-adapted and standard inoculum (a mixed culture of the above mentioned four L. monocytogenes strains) was performed on commercially produced cooked ham $\left(\mathrm{pH} 6.22 \pm 0.13, a_{\mathrm{w}} 0.975 \pm 0.001\right.$ vacuum packaging) and pâté $\left(\mathrm{pH} 6.11 \pm 0.09, a_{\mathrm{w}} 0.966 \pm 0.007\right.$, MAP $\left.\left(30 \% \mathrm{CO}_{2}-70 \% \mathrm{~N}_{2}\right)\right)$. The results of challenge testing of vacuum packed cooked ham slices are shown in Fig. 4. It is clear that vacuum packed cooked ham slices are an at risk product for listeriosis and supports the growth of the pathogen well. In 5 days time, minimum of ca. $2 \log$ increase of the 


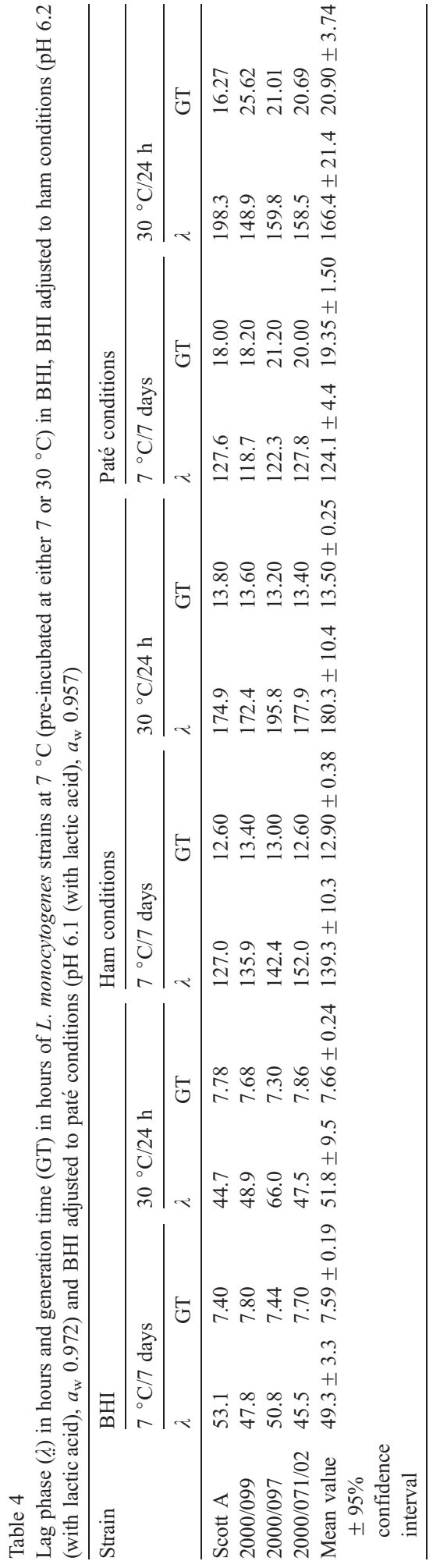

inoculum, whether standard or cold-adapted inoculum, is noticed. Nevertheless, higher numbers of $L$. monocytogenes were obtained and the threshold of $100 \mathrm{cfu} / \mathrm{ml}$ was crossed faster for the cold-adapted inoculum compared to the standard inoculum. The increased effort during the second experiment to eliminate temperature shifts or modification of $a_{\mathrm{w}}$ and $\mathrm{pH}$ due to the inoculation procedure did not retard the onset of growth of the pathogen. In the first two experiments, the initial LAB count was low $\left(3 \times 10^{2} \mathrm{cfu} / \mathrm{ml}\right)$ and $\mathrm{LAB}$ grew to high numbers in 14 days. In the first experiment, inhibition of the growth of L. monocytogenes was noted at day 16 . High numbers of LAB were present $\left(>10^{7} \mathrm{cfu} / \mathrm{ml}\right)$ and $\mathrm{pH}$ had decreased to 5.38. In the second experiment, high numbers of $\operatorname{LAB}\left(>10^{7} \mathrm{cfu} / \mathrm{ml}\right)$ were also present at day 14; however, growth of $L$. monocytogenes continued during the remaining time of the experiment. This may be explained by the fact that $\mathrm{pH}$ remained higher throughout the experiment (pH 6.14 at day 10 and $\mathrm{pH} 6.04$ at day 22). In the third experiment, sliced cooked ham with initial higher numbers of LAB $\left(10^{5} \mathrm{cfu} / \mathrm{ml}\right)$ was obtained. Again L. monocytogenes rapidly crossed the threshold of $100 \mathrm{cfu} / \mathrm{ml}$ (on day 3 for both the coldadapted and standard inoculum) but high numbers of the pathogen as in the other two experiments were not obtained. Growth of L. monocytogenes was inhibited after 7 days at ca. $3 \times 10^{3} \mathrm{cfu} / \mathrm{ml}$ when LAB reached high numbers $\left(>10^{7} \mathrm{cfu} / \mathrm{ml}\right)$ although $\mathrm{pH}$ was 6.12 at that time.

The growth of $L$. monocytogenes and LAB during challenge testing of pâté is shown in Fig. 5. In the first experiment, growth of L. monocytogenes was established although multiplication of the pathogen was slower in pâté than in cooked ham because of the more suboptimal intrinsic and extrinsic conditions. In the first pâté experiment, L. monocytogenes crossed the threshold of $100 \mathrm{cfu} / \mathrm{ml} \mathrm{ca} .10$ days earlier for the cold-adapted inoculum compared to the standard inoculum, after 11 and 21 days of preservation, respectively, at $7{ }^{\circ} \mathrm{C}$. LAB increased to high numbers $\left(>10^{7} \mathrm{cfu} / \mathrm{ml}\right)$ by the end of shelf life (19 days). In the second experiment, a rapid increase of L. monocytogenes was observed and the threshold of $100 \mathrm{cfu} / \mathrm{ml}$ was obtained after 8 and 12 days for the cold-adapted inoculum and the standard inoculum, respectively. Numbers of LAB were limited to $10^{5} \mathrm{cfu} / \mathrm{ml}$ by the 

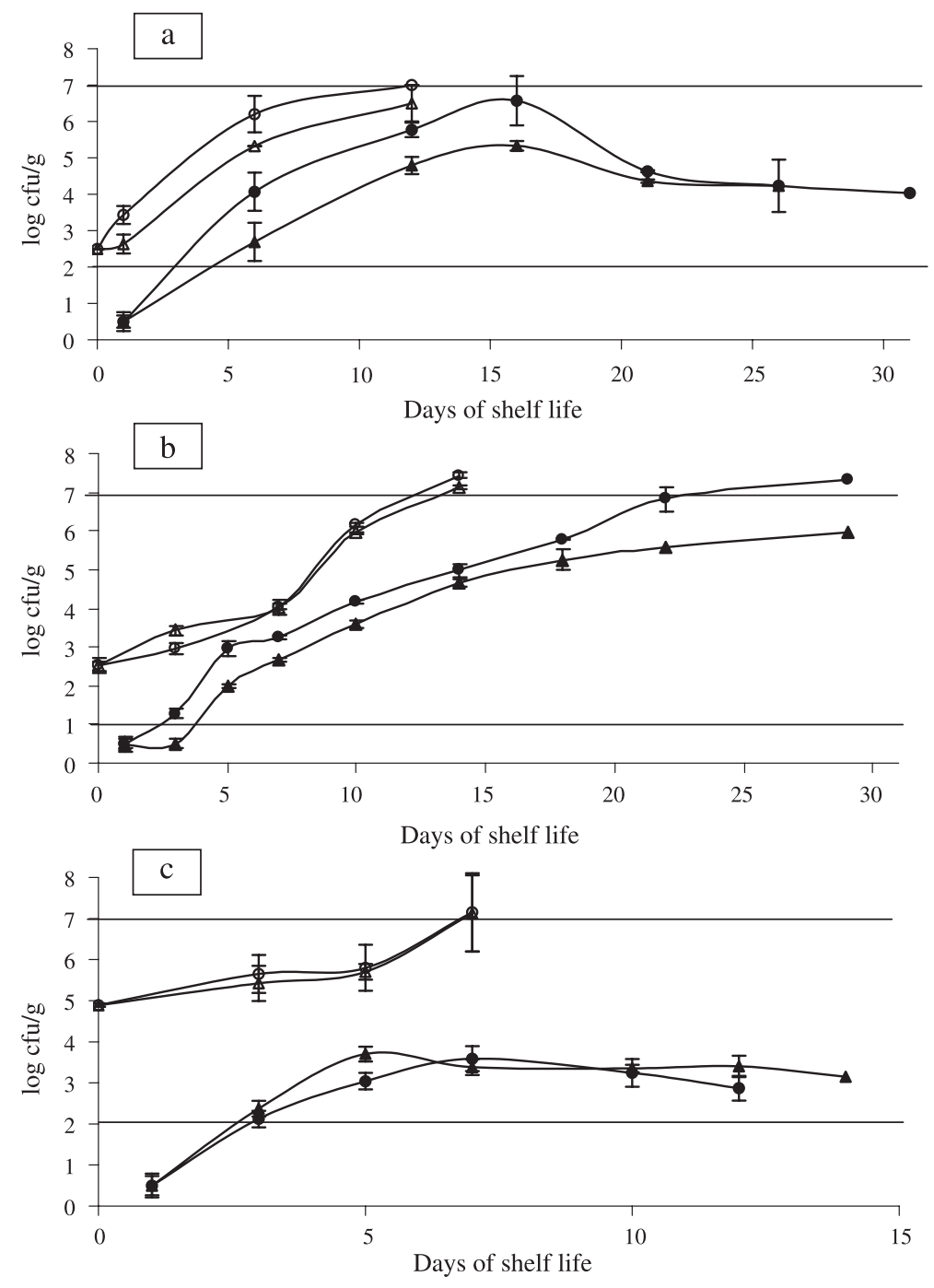

Fig. 4. Growth of L. monocytogenes $(\boldsymbol{\Delta}, \bigcirc)$ and lactic acid bacteria $(\mathrm{O}, \Delta)$ on vacuum packed sliced cooked ham stored at $7{ }^{\circ} \mathrm{C}$ inoculated with a mixed $L$. monocytogenes inoculum pre-incubated at $30{ }^{\circ} \mathrm{C}(\Delta, \mathbf{\Delta})$ or $7{ }^{\circ} \mathrm{C}(\mathrm{O}, \mathbf{O})$ in three different experiments: (a) experiment 1 , (b) experiment 2 and (c) experiment 3. In each graph, the lower line indicates the detection limit of the enumeration method for L. monocytogenes, the upper line indicates the upper limit for lactic acid bacteria indicating end of shelf life.

end of shelf life. Rapid growth of L. monocytogenes might be explained by the low concentrations of sodium lactate in the pâté $(0.15 \%, \mathrm{w} / \mathrm{w})$ whereas the sodium lactate concentrations in cooked meat products can vary from $1 \%$ to $2 \%(\mathrm{w} / \mathrm{w})$ establishing retardation of microbial growth (Debevere, 1989; Devlieghere et al., 2001). The experiment was repeated a third time with pâté with $0.97 \%(\mathrm{w} / \mathrm{w})$ sodium lactate (subsequently, the $a_{\mathrm{w}}$ of the pâté was also slightly reduced (0.957 instead of 0.966)). Under these conditions, L. monocytogenes survived in the pâté (present per gram) but remained beneath the threshold of $100 \mathrm{cfu} / \mathrm{ml}$ during the 19 days shelf life at $7{ }^{\circ} \mathrm{C}$. LAB were also restricted to maximum $10^{4}$ $\mathrm{cfu} / \mathrm{g}$. It can be concluded that growth of L. monocytogenes in the particular pâté product is variable and 

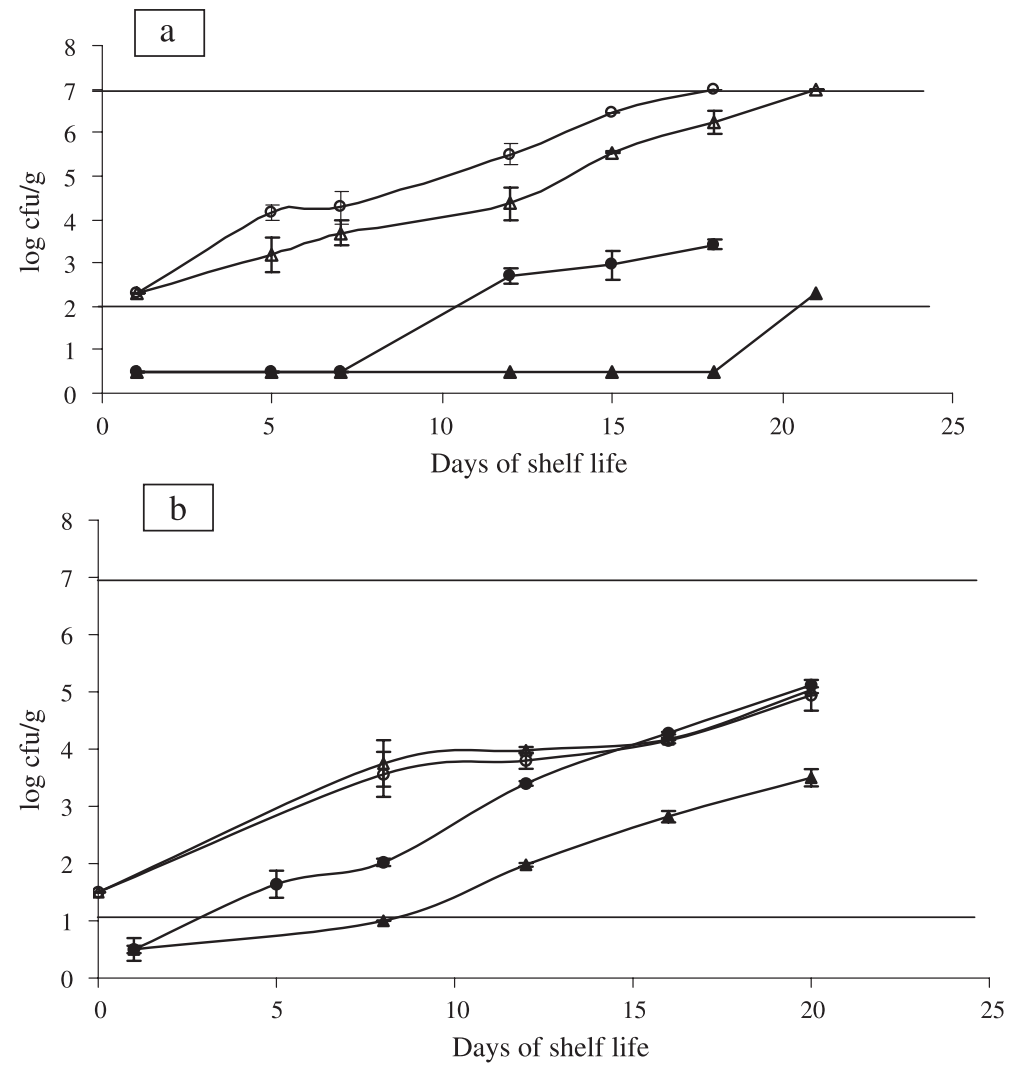

Fig. 5. Growth of L. monocytogenes $(\boldsymbol{\Delta}, \mathbf{O})$ and lactic acid bacteria $(\mathrm{O}, \Delta)$ on MAP pâté stored at $7{ }^{\circ} \mathrm{C}$ inoculated with a mixed L. monocytogenes inoculum pre-incubated at $30^{\circ} \mathrm{C}(\Delta, \mathbf{\Delta})$ or $7{ }^{\circ} \mathrm{C}(\mathrm{O}, \mathbf{O})$ in two different experiments: (a) experiment 1 and (b) experiment 2. In experiment 3, L. monocytogenes remained present per gram but never crossed the threshold of $100 \mathrm{cfu} / \mathrm{g}$. Lactic acid bacteria remained below $10^{5} \mathrm{cfu} / \mathrm{g}$ throughout the 19 days shelf life. In each graph, the lower line indicates the detection limit of the enumeration method for L. monocytogenes, the upper line indicates the upper limit for lactic acid bacteria indicating end of shelf life.

depends upon the exact values of the intrinsic and extrinsic factors of the product.

\section{Discussion}

\subsection{Growth potential of L. monocytogenes in RTE cooked meat products}

A wide range of cooked RTE food products supports multiplication of $L$. monocytogenes. The acceptance of low numbers of $L$. monocytogenes in foods is closely related to the stability of these foods against growth of L. monocytogenes (Codex Alimentarius, 2002). Some data on the potential for growth of L. monocytogenes on cooked RTE meat products are available. Glass and Doyle (1989) showed that regardless of the initial inoculum $(0.2$ or $500 \mathrm{cfu} / \mathrm{g})$, numbers of Listeria attained populations of $10^{5}-10^{6}$ $\mathrm{cfu} / \mathrm{g}$ on organoleptically acceptable cooked ham (vacuum packaged, $\mathrm{pH}$ 6.3-6.5) after 4 weeks of refrigerated storage. Unlike sliced ham, cooked roast beef supported far less growth of Listeria, with populations increasing $>2$ orders of magnitude on organoleptically acceptable product after 4 weeks of refrigerated storage. In a study by Beumer et al. (1996), growth of L. monocytogenes on vacuum packed luncheon meat, cooked ham, and cooked chicken breast meat was similar to that of modified atmosphere packaged (MAP) stored meats, with counts increasing up to $10^{8} \mathrm{cfu} / \mathrm{g}$ after 35 days at $7{ }^{\circ} \mathrm{C}$. 
In the present study, rapid growth of L. monocytogenes was noticed on vacuum packed sliced cooked ham. The concentration of $100 \mathrm{cfu} / \mathrm{g}$, the safety limit considered as low risk for causing listeriosis, was exceeded after 5 days whereas ca. $10^{5} \mathrm{cfu} / \mathrm{g}$ were obtained after 14 days. It is established that LAB are present on sliced cooked ham due to post-contamination but the type and level of LAB and the characteristics of these LAB (psychrotrophic character, acidity produced, bacteriocin production) may vary and may influence the interaction of these LAB with L. monocytogenes and the opportunities for growth of the pathogen. Nevertheless, in all three experiments, it was observed that at the time the indigenous LAB attained high numbers $\left(>10^{7}\right.$ $\mathrm{cfu} / \mathrm{ml}$ ) limiting the shelf life of the product (ca. 14 days), L. monocytogenes was already present in unacceptable high numbers endangering the public health. As such, a zero tolerance of L. monocytogenes should be established for this particular RTE meat product or the formulation or packaging method of the product should be modified in order to control the growth of L. monocytogenes.

For pâté the situation was not straightforward. The concentration of sodium lactate determined the opportunities for growth of L. monocytogenes. Various factors determine the fate of Listeria on a cooked meat surface. The most important factors are $\mathrm{pH}, a_{\mathrm{w}}, \mathrm{NaCl}$, sodium nitrite, sodium lactate, atmosphere, length and temperature of storage (ICMSF, 1996; Schott and Hildebrandt, 1996). Predictive models have been developed including some of these factors (McClure et al., 1997; Nerbrink et al., 1999; Augustin and Carlier, 2000; Devlieghere et al., 2001) and may be helpful to describe growth of L. monocytogenes in at risk foods. However, other factors should also be considered such as strain type (Begot et al., 1997), inoculum size (Robinson et al., 2001), history (Gay et al., 1996; Augustin et al., 2000), interactions with competitive flora, e.g. LAB or interactions with the food product (antimicrobial components, biological structures). In addition, recent work modelling the behaviour of bacteria in foods has shown that the lag phase is more difficult to predict than is the specific growth rate (Robinson, 2001). Challenge testing of the food product with L. monocytogenes is recommended to assess the potential for growth both qualitatively and quantitatively in the foods at risk.
4.2. Challenge testing to establish growth of $L$. monocytogenes in RTE cooked meat products

\subsubsection{Choice of L. monocytogenes strain}

Recently, AFSSA (2001) issued a specific proposal for challenge testing of $L$. monocytogenes in at risk foods. The AFFSA protocol suggests using of two strains, a food isolate and a reference strain, separately in a challenge test. The use of a food isolate is recommended because it is likely to represent better the behaviour of a naturally contaminating strain. The use of a reference strain is recommended because it allows the comparison of the outcome of challenge tests in different settings. In the present study, the option was taken to use a mixed inoculum. As major outbreaks have been associated with serotype $4 \mathrm{~b}$ whereas serotype $1 / 2 \mathrm{a}$ is most often recovered from food (Norrung, 2000), it is relevant to include preferentially strains of these serotypes in the mixed inoculum. The use of a mixed inoculum also circumvents variations in growth and survival that might occur between strains under different suboptimal conditions. The strains used in the inoculum were selected from a range of strains prior characterized (acid resistance, behaviour under suboptimal conditions) to establish that the strains used for the challenge test are representative for the behaviour of $L$. monocytogenes under these conditions. It was noted, as did Begot et al. (1997) when investigating the growth variability among Listeria strains, that strains exhibiting the longest generation time did not show the maximal lag time and, similarly, the strain exhibiting the shortest generation time did not show the shortest lag time. As such, there is not one L. monocytogenes strain which manifests slow or fast growth in all four conditions. Begot et al. (1997) testing 66 Listeria strains (isolates from meat products and industrial sites) under four conditions did find differences between strains especially in lag phase duration when strains were subjected to stress conditions ( $a_{\mathrm{w}}$ adjusted to 0.96 with $\mathrm{NaCl}$ or $\mathrm{pH} 5.6$ at $10{ }^{\circ} \mathrm{C}$ ) whereas the majority of the strains isolated from industrial sites showed faster growth than the other strains. There were only 11 strains in our study, no isolates from industrial sites were implicated and neither were the combined stress conditions as severe as in the study by Begot et al. (1997). The maximal mean lag time was $6 \mathrm{~h}$ in our study whereas mean lag times mentioned by Begot et 
al. (1997) were 28.2 and $16.6 \mathrm{~h}$ for respectively $a_{\mathrm{w}}$ 0.96 and $\mathrm{pH} 5.6$ at $10{ }^{\circ} \mathrm{C}$. This may explain why all our strains showed an average behaviour in the experimental conditions tested.

\subsubsection{Choice of inoculum level}

The protocol of AFSSA (2001) recommends an inoculum level of ca. $1000 \mathrm{cfu} / \mathrm{g}$. This inoculum level is commonly used in challenge testing because this enables enumeration. However, these high inoculum levels are not representative for the natural contamination of $L$. monocytogenes commonly encountered in RTE foods. A challenge test in which the inoculum contains too many organisms may overstress the preservative system of a product which would not normally be at risk and lead to an overestimation of the risk, whereas too few organisms may give false negative results (Rose and Stringer, 1987). Studies have shown that beneath the common inoculation level of $1000 \mathrm{cfu} / \mathrm{ml}$, the lag phase becomes longer and the probability of growth is less (Gay et al., 1996; Robinson et al., 2001; Pascual et al., 2001). Farber and Daley (1994) found that when L. monocytogenes was present in very low numbers on meats such as sliced ham, turkey breasts, wieners, and pâté stored at $4{ }^{\circ} \mathrm{C}$, its numbers did not increase. In the present study, the option was taken to use an inoculum level of ca. 1-10 $\mathrm{cfu} / \mathrm{g}$ which is in agreement with L. monocytogenes concentrations detected in RTE cooked meat products (Uyttendaele et al., 1999). As the inoculum was administered by disposal of $100 \mu \mathrm{l}$ on a 50 -g portion, the inoculum contains ca. $100 \mathrm{cfu}$ per portion. This is a high enough number of cells in order to make the inoculation procedure statistically reliable (minimal variation in the number of cells per portion inoculated). This inoculum size (ca. $100 \mathrm{cfu}$ per portion) should also be high enough to eliminate any effect on the lag phase and capacity for growth. It was shown that in media with suboptimal conditions for growth, both the mean lag time and variation between replicate inoculum increased as the inoculum size became smaller (Robinson et al., 2001). The effect of inoculum size for stationary phase cells would only be affected for numbers of less than 100 cells (Robinson et al., 2001; Gay et al., 1996) except for extreme stress conditions (growth/ no growth boundary) (Robinson et al., 2001; Pascual et al., 2001). As low numbers were inoculated on the
RTE meat products, initially enumeration of the pathogen on the samples was not possible. The option was taken to make a semi-quantitative approach determining presence/absence of the pathogen per $25 \mathrm{~g}$ and per gram. As such, it was established that the initial inoculum of the pathogen in the RTE meat product was as expected (ca. $1-5 \mathrm{cfu} / \mathrm{g}$ ) and the pathogen survived. Enumeration was performed in order to establish whether the pathogen crossed the threshold of $100 \mathrm{cfu} / \mathrm{g}$.

\subsubsection{Effect of pre-incubation temperature}

AFSSA (2001) recommends pre-incubation of the inoculum at a temperature resembling the storage temperature of the product. In the present study, $L$. monocytogenes cultures were pre-incubated at either 7 or $30{ }^{\circ} \mathrm{C}$. From the experiment performed in microtitre plates, it was observed that the temperature history had a significant effect on the lag phase duration which confirms previous studies which have also reported that the lag time before re-growth at low temperature has been observed shorter with low than with high preincubation temperatures (Augustin et al., 2000). In the actual microbial challenge testing of RTE meat products, there was a trend to a shorter lag phase and thus a faster crossing of the threshold of $100 \mathrm{cfu} / \mathrm{g}$ for the cold-adapted inoculum and these effects were more pronounced for the pâté samples than for the cooked ham samples. Especially in the more suboptimal conditions for growth, the effect of pre-incubation temperature enabling adaptation of the inoculum to the storage temperature may be of significance to the outcome of the challenge test.

\subsubsection{Establishment of product categories for challenge testing}

It must be stressed that as many factors influence multiplication of L. monocytogenes in a food product, it is of importance that experimental design and interpretation of the results of a challenge test is performed by an experienced food microbiologist with knowledge of the ecology and technology of the food product involved. The test results of the pâté show how difficult it will be to establish opportunities for growth of $L$. monocytogenes for a whole product group, e.g. "pâté". It will need to be examined for each individual product whether L. monocytogenes can multiply under the prevailing conditions of storage and distribution and 
how rapidly they can multiply in order the establish the stability of the product against growth of L. monocytogenes. An alternative approach could be to group food products according to the intrinsic and extrinsic parameters of foods that affect microbial growth (Mossel et al., 1995; Jay, 2000). The main factors to be taken into consideration are $\mathrm{pH}, a_{\mathrm{w}}$, composition of the food product (nitrite, organic acids, etc.), natural antimicrobial components, biological structures, temperature, atmosphere, and competitive flora. It is a scientific sound and interesting option to group foods based on the "barrier" or "hurdle" set by the main factors influencing the rate of growth of each micro-organism rather than working out categories of foods solely based on origin (dairy, meat, fish, vegetable), heat treatment (raw or cooked) and epidemiological association with listeriosis in order to establish their stability towards growth of L. monocytogenes and determine their status as at risk food product for listeriosis.

Challenge testing will become an important tool in evaluating the risk associated with RTE food product for listeriosis; however, challenge testing is only one of the tools available and should be used in addition to predictive modelling, end product control, GMP and HACCP to control the risk for listeriosis due to consumption of RTE food products.

\section{Acknowledgements}

This research is supported by the Second MultiAnnual Scientific Support Plan for a Sustainable Development Policy, initiated by the Belgian State, Prime Minister's Office for Science, Technology and Culture. The authors thank the Special Research Fund of the University of Gent for providing a doctoral fellowship to A. Rajkovic. M. Uyttendaele is indebted to the Fund for Scientific ResearchFlanders for a position as a Postdoctoral Research Assistant.

\section{References}

AFSSA, 2001. Avis de l'Agence française de sécurité sanitaire des aliments relatif à la classification des aliments selon le danger représenté par Listeria monocytogenes. 29/10/01.

Anonymous, 1991. Listeria in food. Report of the West and North
Yorkshire Joint Working group on a two year survey of the presence of Listeria in food. Environ. Health 99, 132-137.

Anonymous, 1997. Microbiological Monitoring of Ready-to-Eat Products, 1993-1996 United States Department of Agriculture, Food Safety and Inspection Service, Washington, DC.

Augustin, J.-C., Carlier, V., 2000. Mathematical modelling of the growth rate and lag time for Listeria monocytogenes. Int. J. Food Microbiol. 56, 29-51.

Augustin, J.-C., Brouillaud-Delattre, A., Rosso, L., Carlier, V., 2000. Significance of inoculum size in the lag time of Listeria monocytogenes. Appl. Environ. Microbiol., 1706-1710.

Baranyi, J., Roberts, T.A., 1994. A dynamic approach to predicting bacterial growth in food. Int. J. Food Microbiol. 23, 277-294.

Begot, C., Lebert, I., Lebert, A., 1997. Variability of the response of 66 Listeria monocytogenes and Listeria innocua strains to different growth conditions. Food Microbiol. 14, 403-412.

Beumer, R.R., te Giffel, M.C., de Boer, E., Rombouts, F.M., 1996. Growth of Listeria monocytogenes on sliced cooked meat products. Food Microbiol. 13, 333-340.

Bolton, L.F., Frank, J.F., 1999. Simple method to observe the adoptive response of Listeria monocytogenes in food. Lett. Appl. Microbiol. 29, 350-353.

Buchanan, R., Damert, W., Whiting, R., van Schothorst, M., 1997. Use of epidemiologic and food survey data to estimate a purposefully conservative dose-response relationship for L. monocytogenes levels and incidence of listeriosis. J. Food Prot. 60 (8), 918-922.

CDC, 2002. Update: listeriosis outbreak investigation Published at: (http://www.cdc.gov/od/oc/media/pressrel/r021015.htm).

Codex Alimentarius, 2002. Report of the Thirty-Fourth Session of the Codex Committee on Food Hygiene (ALINORM 03/13). FAO/WHO, Rome, Italy.

Debevere, J., 1989. The effect of sodium lactate on the shelf life of vacuum-packaged coarse liver pâté. Fleischwirtschaft 69 , $223-224$.

Devlieghere, F., Geeraerd, A.H., Versyck, K.J., Van De Waetere, B., Van Impe, J., Devbevere, J., 2001. Growth of Listeria monocytogenes in modified atmosphere packaged cooked meat products: a predictive model. Food Microbiol. (18-I), 53-66.

European Commission, 2000. Draft commission decision on the control of Listeria monocytogenes in ready-to-eat food. Working document, Commission of the European Communities, Brussels, Belgium.

Farber, J.M., Daley, E., 1994. Presence and growth of Listeria monocytogenes in naturally-contaminated meats. Food Microbiol. 22, 33-42.

Farber, J., Peterkin, P., 1991. Listeria monocytogenes: a food-borne pathogen. Microbiol. Rev. 55, 476-511.

Farber, J., Peterkin, P., 1999. Incidence and behaviour of Listeria monocytogenes in meat products. In: Ryser, E.T., Marth, E.H. (Eds.), Listeria, Listeriosis and Food Safety. Marcel Dekker, New York, pp. 505-565.

Francois, K., Devlieghere, F., Standaert, A.R., Geeraerd, A.H., Van Impe, J.F., Debevere, J., 2003. Modelling the individual cell lag phase. Isolating single cells: protocol development. Lett. Appl. Microbiol. 37 (1), 26-30.

Gahan, C.G.M., O’Driscoll, B., Hill, C., 1996. Acid adaptation 
of Listeria monocytogenes can enhance survival in acid foods and during milk fermentation. Appl. Environ. Microbiol., 3132-3218.

Gay, M., Cerf, O., Davey, K.R., 1996. Significance of pre-incubation temperature and inoculum concentration on subsequent growth of Listeria monocytogenes at $14{ }^{\circ} \mathrm{C}$. J. Appl. Bacteriol. 81, 433-438.

Glass, K.A., Doyle, M.P., 1989. Fate of Listeria monocytogenes in processed meat products during refrigerated storage. Appl. Environ. Microbiol. 55, 1565-1569.

Goulet, V., Rocourt, J., Rebiere, I., Jacquet, C., Moyse, C., Dehaumont, P., Salvatm, G., Veit, P., 1993. Listeriosis outbreak associated with the consumption of rillettes in France in 1993. J. Infect. Dis. 177, 155-160.

ICMSF, 1996. Micro-organisms in foods: 5. Microbiological Specifications of Food Pathogens-Listeria monocytogenes, Chapter 8. Blackie Academic \& Professional, Chapman \& Hall, London, UK, pp. 141-182.

ICMSF, 2002. Micro-organisms in foods: 7. Microbiological Testing in Food Safety Management. Kluwer Academic Publishing, New York, NY, pp. 285-309. Chapter 16.

Jay, J.M., 2000. Modern Food Microbiology. Aspen Publishers, Gaithersburg, MD, pp. 35-56.

Leistner, L., 2000. Minimally processed, ready-to-eat and ambient stable meat products. In: Man, D., Jones, A. (Eds.), Shelf-Life Evaluation of Foods. Aspen Publishers, Gaithersburg, MD, pp. $242-263$.

Lund, B., 2000. Listeria monocytogenes in ready-to-eat foods (Letter to the Editor). Food Saf. Express 1 (4), 3-4.

McClure, P.J., Beaumont, A.L., Sutherland, J.P., Roberts, T.A., 1997. Predictive modeling of growth of Listeria monocytogenes - the effects on growth of $\mathrm{NaCl}, \mathrm{pH}$, storage temperature and $\mathrm{NaNO}_{2}$. Int. J. Food Microbiol. 34 (3), 221-232.

Mossel, D.A.A., Corry, J.E.L., Struijk, C.B., Baird, R.M., 1995. Essentials of the Microbiology of Food. Wiley, Chichester, England, pp. 63-110.

Nerbrink, E., Borch, E., Blom, H., Nesbakken, T., 1999. A model based on absorbance data on the growth rate of Listeria monocytogenes and including the effects of $\mathrm{pH}, \mathrm{NaCl}$, sodium lactate and sodium acetate. Int. J. Food Microbiol. 47 (1/2), 99-109.

Noack, D.J., Joeckel, J., 1993. Listeria monocytogenes, occurrence and significance in meat and meat products and experience with recommendations for its detection and assessment. Fleischwirtschaft $73,581-584$.

Norrung, D.V.M., 2000. Microbiological criteria for Listeria monocytogenes in foods under special consideration of risk assessment approaches. Int. J. Food Microbiol. 62, 217-221.

Notermans, S., in 't Veld, P., 1994. Microbiological challenge testing for ensuring safety of food products. Int. J. Food Microbiol. $24,33-39$.

Pascual, C., Robinson, T.P., Ocia, M.J., Aboaba, O.O., Mackey, B.M., 2001. The effect of the inoculum size and sublethal injury on the ability of Listeria monocytogenes to inititae growth under suboptimal conditions. Lett. Appl. Microbiol. 33, 357-361.

Robinson, T.P., Kaloti, A., Ocio, M.J., Mackey, B.M., 1998. The effect of the growth environment on the lag phase of Listeria monocytogenes. Int. J. Food Microbiol. 44, 83-92.

Robinson, T.P., Aboaba, O.O., Kaloti, A., Ocio, M.J., Baranyi, J., Mackey, B.M., 2001. The effect of inoculum size on the lag phase of Listeria monocytogenes. Int. J. Food Microbiol. 70, $163-173$.

Rose, S.A., Stringer, M.F., 1987. Guidelines for Microbiological Challenge Testing. Campden \& Chorleywood Food Research Association Group. Technical Manual No. 20.

Ross, T., Todd, E., Smith, M., 2000. Exposure assessment of Listeria monocytogenes in ready-to-eat foods. Preliminary Report for Joint WHO/FAO Expert Consultation on Risk Assessment of Microbiological Hazards in Foods. FAO, Rome.

Ryser, E.T., 1999. Foodborne listeriosis. In: Ryser, E.T., Marth, E.H. (Eds.), Listeria, Listeriosis and Food Safety. Marcel Dekker, New York, NY, pp. 299-358.

Schott, W., Hildebrandt, G., 1996. Listeria in processed meat products. Meat Int. 6 (8), $42-45$.

Uyttendaele, M., De Troy, P., Debevere, J., 1999. Incidence of Listeria monocytogenes in different types of meat products on the Belgian retail market. Int. J. Food Microbiol. 53 (1), $75-80$.

Vlaemynck, G., Lafarge, V., Scooter, S., 2000. Improvement of the detection of Listeria monocytogenes by the application of ALOA, a diagnostic, chromogenic isolation medium. J. Appl. Microbiol. 88, 430-441. 